\title{
SIMULATION-OPTIMIZATION INTEGRATED APPROACH TO PLANNING READY MIXED CONCRETE PRODUCTION AND DELIVERY: VALIDATION AND APPLICATIONS
}

\author{
Ming Lu \\ Hoi-Ching Lam \\ Dept. of Civil \& Structural Engineering \\ Hong Kong Polytechnic University \\ Hong Kong, China
}

\begin{abstract}
Powered by the simulation and optimization engines resulting from recent research, a computer system named HKCONSIM is ready to provide concrete plant managers with decision support in making the best operation strategy for delivering concrete to multiple site clients. This paper demonstrates case studies of HKCONSIM applications in practical settings with emphasis on addressing two questions: (1) "Can HKCONSIM capture the complexities of the real world?" and (2) "How to take advantage of HKCONSIM to attain customer satisfaction and cost effectiveness?" A case study describing one-day operations of the batch plant is used to illustrate the decision support functions HKCONSIM can provide. The case study consists of four parts: (1) input data preparation, (2) the definitions of relevant measures of the system performance, (3) simulation model validation by comparing the simulation outputs against the actual records, and (4) further optimization analysis under three "what-if" scenarios postulated with practical implications. In conclusion, the batch plant operators can draw on HKCONSIM to augment their experiences, corroborate their intuitions, and create new intelligence in coping challenges in day-by-day operations planning.
\end{abstract}

\section{INTRODUCTION}

The benefits of ready mixed concrete (RMC) in light of attaining consistent quality standards, being environmentallyfriendly, and demanding less site space have accounted for its ubiquitous application in infrastructure and residential building projects. The scheduling of RMC production and delivery is essentially a problem of materials logistics planning, which is "a decision process for strategically managing the procurement, movement and storage of raw materials, finished product inventory and the related information flows throughout the organization and its marketing channels in such a way that the current and future profitability is maximized by cost-effective fulfillment of orders" (Christopher 1992). In Hong Kong, a RMC plant generally requires a three-day advance notice for ordering concrete delivery service, with the order confirmed one day before the actual pour date. Raw material stocks at a plant are replenished on a daily basis in preparation for the next-day's production which is pulled by site orders placed by multiple clients. A RMC plant transforms raw materials into concrete in its production facility and is committed to delivering concrete to different construction sites by truckmixers so as to match the onsite concreting progresses. The elapsed duration from the introduction of water to the final placement of the concrete is of particular importance to the quality control of ready mixed concrete. For example, ASTM C94 (ASTM 2000) allows a maximum of 1.5 hours (90 minutes), or before the drum has made 300 revolutions, whichever comes first. The Hong Kong common practice is to unload concrete into the forms on site within $1 \mathrm{hr} 45 \mathrm{~min}$ of first mixing as a maximum time limit. Due to the perishable nature of concrete, the batching and delivery operation of the RMC industry is a classic example of Just-InTime (JIT) construction system (Tommelein and Li 1999).

The dispatching of truckmixers to fulfill site orders is not only constrained by the availability of plant resources (i.e. the batch bay and the truckmixers), but also driven by the demand pattern of concrete by the sites. Thus, the service levels achieved together with the utilization levels achieved for the resources involved are governed by the subtle interactions between the supply and demand factors. The supply is mainly constrained by (1) the resources available at the RMC plant (including mixers and trucks) and (2) the mechanisms for scheduling concrete production and dispatching truckmixers to different sites; while the clients' demand is characterized in terms of (1) the total number and location distribution of sites being 


\section{Lu and Lam}

served simultaneously, (2) the grade and quantity of concrete for each site, (3) the traveling distance or time from the plant to each site, and (4) the concrete-unloading rate on each pour. Nonetheless, in confronting the complexity, uncertainty and variability within a one-plant-multisite RMC production system of practical size, the current industry practices still largely rely on managerial experiences and heuristic methods, falling short on any effective, straightforward modeling and optimization means to support decision making. Anson and Wang (1994) highlighted the negative effect of the poor coordination between RMC plants and site contractors on the productivity of concreting processes. The relatively poor matching performance between the supply of concrete and the site requirements in Hong Kong building sites was characterized by both truckmixers' queuing on site and site crews staying idle due to late truckmixers' arrivals (Anson and Wang 1998). In addition, the relatively poor matching performance between the concrete supply and the site requirements also caused the serious underutilization of plant resources - an average of $37.6 \%$ in terms of truckmixer working percentage was reported as of Hong Kong's experience (Anson et al. 2002). This has undermined not only the efficiency and service of the RMC business, but also the productivity and quality of concrete construction in building sites.

Simulation modeling of complicated, dynamic, and interactive processes in construction is essentially a computersupported implementation of the systems approach. Riley and Towill (2001) define a system as "an integrated combination of the components and activities, designed to follow a common purpose and exists in order to achieve a better understanding of the problem and hence help create a 'tool' to resolve the problem". Discrete-event simulation keeps track of the changes of the state of a system occurring at discrete points in time (Pidd 1992); and actually builds a logical model of a system for experimenting with it on a computer (Pritsker 1986). As a matter of fact, the methodology of discrete-event simulation is the only general methodology that affords a means of modeling the ready-mixed concrete production and construction systems on a stochastic basis (Zayed and Halpin 2001). Research has proven the power and capability of the simulation technology in tackling the concrete production systems subject to practical constraints. Smith (1998) simulated the stochastic concrete delivery and pumping process with a spreadsheet program, observing the optimal combination of truck interarrival and concrete pump times that would maximize the plant utilization while minimizing the pour duration. Ying et al. (2005) also identified the importance of a site manager specifying realistic time intervals between consecutive truckmixer arrivals by conducting simulation experiments on a VB program developed in house. In addition, Sawhney et al. (1999) described the utilization of Petri nets as a process modeling and analysis tool for deciding the least number of concrete trucks that would lead to the maximum daily production rate in fulfilling the daily site orders at a RMC plant. Chau and Li (2002) developed a resourceinteracted simulation modeling approach to analyze general construction operations and particularly employed it to model a concrete delivery operation. Alkoc and Erbatur (1998) and Zayed and Halpin (2001) utilized the simulation system of MicroCYCLONE to generate simulation models for concreting operations and evaluate a set of possible resource combinations. Zayed and Minkarah (2004) also designed a linear programming model to determine the optimal number of transit mixers based upon the required quantity of concrete. Based on a simplified discrete-event simulation approach (SDESA) for modeling construction operations ( $\mathrm{Lu} 2003$ ), Lu et al. (2003) developed a special-purpose simulation tool called HKCONSIM for rapidly building a simulation model for a typical one-plant-multisite system of concrete production and delivery, thus facilitating the study of the complicated relationships between the pattern of demand for concrete, the resources available to the system, and the service levels achieved together with the utilization levels achieved for the resources involved.

To automatically identify the optimum solution through simulation, evolutionary computing-based optimization algorithms have been integrated with simulation modeling to augment simulation's power in dealing with complex RMC operation planning. By linking up two commercial software systems (the Provess V3 and the Evolver), Hegazy and Kassab (2004) combined the simulation and genetic algorithms (GA) to optimize the resource configuration in placing columns (i.e. the quantities of trucks, crane-buckets, and crews), so as to minimize the unit production cost. Feng et al. (2004) and Feng and $\mathrm{Wu}$ (2006) incorporated the standard and enhanced forms of GA (called fast messy GA) with MicroCYCLONE - respectively - to optimize the schedule of dispatching RMC trucks to multiple construction sites, aimed at yielding the minimum truck waiting time on site while also avoiding concrete supply interruptions. One common limitation noted in the above three GA-optimized simulation models is that the input parameters (such as the traveling duration and casting duration) are simply represented with deterministic values instead of statistical distributions. It is noteworthy that GA has also been embedded in HKCONSIM featuring stochastic input models to simultaneously optimize (1) the production and delivery scheduling and (2) the truckmixer resource provision (Lu 2002). Lu and Lam (2005) further augmented the HKCONSIM modeling platform by incorporating the mortar batching, delivery, and flushing processes for those pumped concrete pours; what is more, two measures of the system performance were compared through GA-enabled optimization, namely, the "site service level" (the summation of crew idle time due to tardy concrete deliveries on all the sites), and the "total operations inefficiency" (the summation of crew idle time plus truckmixer queuing time on all sites). And minimization of the "total operations inefficiency" was found to be the proper objective for optimizing the overall system performance (Lu and Lam 2005). A follow-up attempt was to accelerate the optimization process of HKCONSIM by devising a particle swarm optimization (PSO)-based technique for coping with the optimization of stochastic system simulations (Lu et al. 2006). A comparison of 
PSO with GA was made in the context of optimizing an 11-site HKCONSIM model, showing the PSO-based approach could rapidly (in order of a few minutes) converge at the minimum level for the "total operations inefficiency" while GA failed to converge or required long time (in order of hours) in search of the minimum (Lu et al. 2006).

Hence, the latest HKCONSIM system, powered by the SDESA simulation engine and the PSO-based optimization engine, is ready to provide concrete plant managers with direct assistance in coping with the challenges of generating the best operation strategy in delivering concrete to multiple site clients. Instead of elaborating on the underlying algorithms and the in-house development of the HKCONSIM system, this paper is intended to address such questions as of (1) "Can HKCONSIM capture the complexities of the real world?" and (2) "How to take advantage of HKCONSIM to attain customer satisfaction and cost effectiveness?" Accordingly, particular emphasis is placed on validation and application of this simulation-optimization integrated solution to planning RMC plant operations in a practical setting. The remainder of this paper presents a case study describing one-day operations of a Hong Kong RMC plant for illustrating what kinds of decision support HKCONSIM can provide and how RMC plant operators can take advantage of HKCONSIM to augment their experiences, corroborate their intuitions, and create new intelligence in coping with their day-by-day business. The case study spans (1) input data preparation, (2) the definitions of relevant measures of the system performance, (3) simulation model validation by comparing the simulation outputs against the actual records, and (4) further optimization analysis under three "what-if" scenarios postulated with practical implications. Conclusion is drawn at the end.

\section{2}

\section{VALIDATION OF SIMULATION: CAN HKCONSIM CAPTURE THE COMPLEXITIES OF THE REAL WORLD?}

\subsection{Input Data}

For validating the HKCONSIM simulation platform and further demonstrating simulation-based optimization analysis, one day of complete, detailed operations data (including pour orders, truck-dispatching schedules, concrete delivery slips) were obtained from a concrete plant situated near Tin Wan, Hong Kong Island. As illustrated in Figure 1, corresponding one-plantmulti-site simulation models for concrete orders is formed in HKCONSIM. On that particular day, the plant utilized two batching bays (mixers), 29 large mixer trucks ( $7 \mathrm{~m}^{3}$ volume capacity each) and 15 small ones $\left(5 \mathrm{~m}^{3}\right.$ volume capacity each) to deliver a total of $952 \mathrm{~m}^{3}$ concrete to 13 different building sites. Table 1 gives specifics of the pour orders from 13 sites. Note a pour order provides information on (1) the grade and quantity of concrete ordered, (2) the site location, (3) the particular requirement on the mixer truck type (namely, requesting the delivery service by small truck only, or big truck only, or no requirement), (4) the pour start time (i.e. the arrival time of the first mixer truck), and (5) the estimated supply rate (approximated in terms of the interval time between consecutive truck arrivals, or the quantity of concrete delivered per hour $\mathrm{m}^{3} / \mathrm{hr}$ ).

Table 1: Details of pour orders processed over one working day

\begin{tabular}{|c|c|c|c|c|c|c|}
\hline $\begin{array}{c}\text { Site } \\
\text { ID }\end{array}$ & $\begin{array}{l}\text { Qty. } \\
\left(\mathbf{m}^{3}\right)\end{array}$ & $\begin{array}{l}\text { Spec. } \\
\text { Truck }\end{array}$ & $\begin{array}{c}\text { First } \\
\text { Arrival }\end{array}$ & \begin{tabular}{|c} 
Inter- \\
arrival \\
Time \\
(min)
\end{tabular} & $\begin{array}{l}\text { Dist. } \\
\text { (km) }\end{array}$ & $\begin{array}{l}\text { Placing } \\
\text { Method }\end{array}$ \\
\hline 1 & 78 & Either & $8: 30$ & 25 & $3 \sim 4$ & Pump \\
\hline 2 & 4 & Either & $10: 45$ & - & $3 \sim 4$ & Direct Tip \\
\hline 3 & 5 & Either & $14: 30$ & - & $3 \sim 4$ & Direct Tip \\
\hline 4 & 116 & $7 \mathrm{~m}^{3}$ & $11: 00$ & 20 & $3 \sim 4$ & Two Skips \\
\hline 5 & 129 & $7 \mathrm{~m}^{3}$ & $9: 30$ & 24 & $3 \sim 4$ & Two Skips \\
\hline 6 & 54 & $7 \mathrm{~m}^{3}$ & $13: 00$ & 25 & $3 \sim 4$ & Two Skips \\
\hline 7 & 206 & $7 \mathrm{~m}^{3}$ & $10: 30$ & 14 & $3 \sim 4$ & Pump \\
\hline 8 & 88 & $7 \mathrm{~m}^{3}$ & $10: 45$ & 25 & $6 \sim 10$ & Two Skips \\
\hline 9 & 54 & Either & $12: 00$ & 20 & $6 \sim 10$ & Two Skips \\
\hline 10 & 88 & $7 \mathrm{~m}^{3}$ & $10: 20$ & 30 & $4 \sim 5$ & Two Skips \\
\hline 11 & 16 & $5 \mathrm{~m}^{3}$ & $14: 00$ & 40 & $4 \sim 5$ & Direct Tip \\
\hline 12 & 53 & Either & $13: 15$ & 20 & $4 \sim 5$ & Two Skips \\
\hline 13 & 61 & Either & $9: 00$ & 30 & $4 \sim 5$ & Two Skips \\
\hline
\end{tabular}




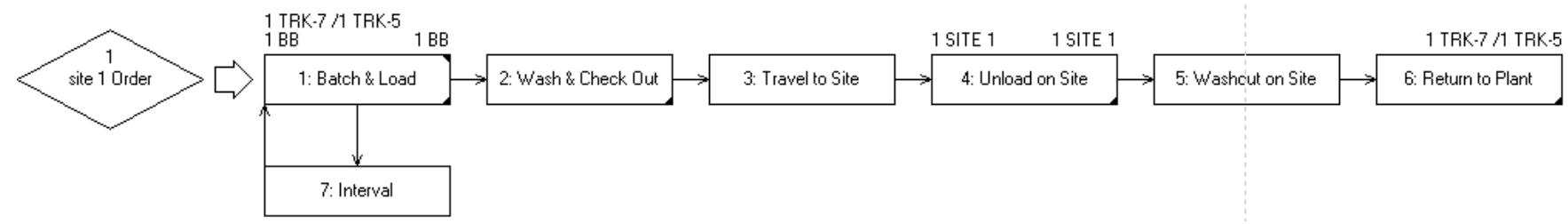

Figure 1: Simulation model of one concrete order in HKCONSIM

The plant-to-site travel distance and the placing method employed for each site are linked to the default triangular distributions for travel times and truck-unloading production rates (as shown in Figure 2, input parameters for triangular distributions are in the order of the optimistic, the pessimistic, and the most likely time estimates in min). The default three-point parameters of HKCONSIM are estimated based on historical data collected in Hong Kong and can be readily adjusted to stay current. In our case study, most default time parameters closely reflect the actual situations, except that the truck-unloading times for seven large pours (ordering more than $70 \mathrm{~m}^{3}$ ) need reassessment and adjustment according to the actual site truckunloading time records (Table 2).

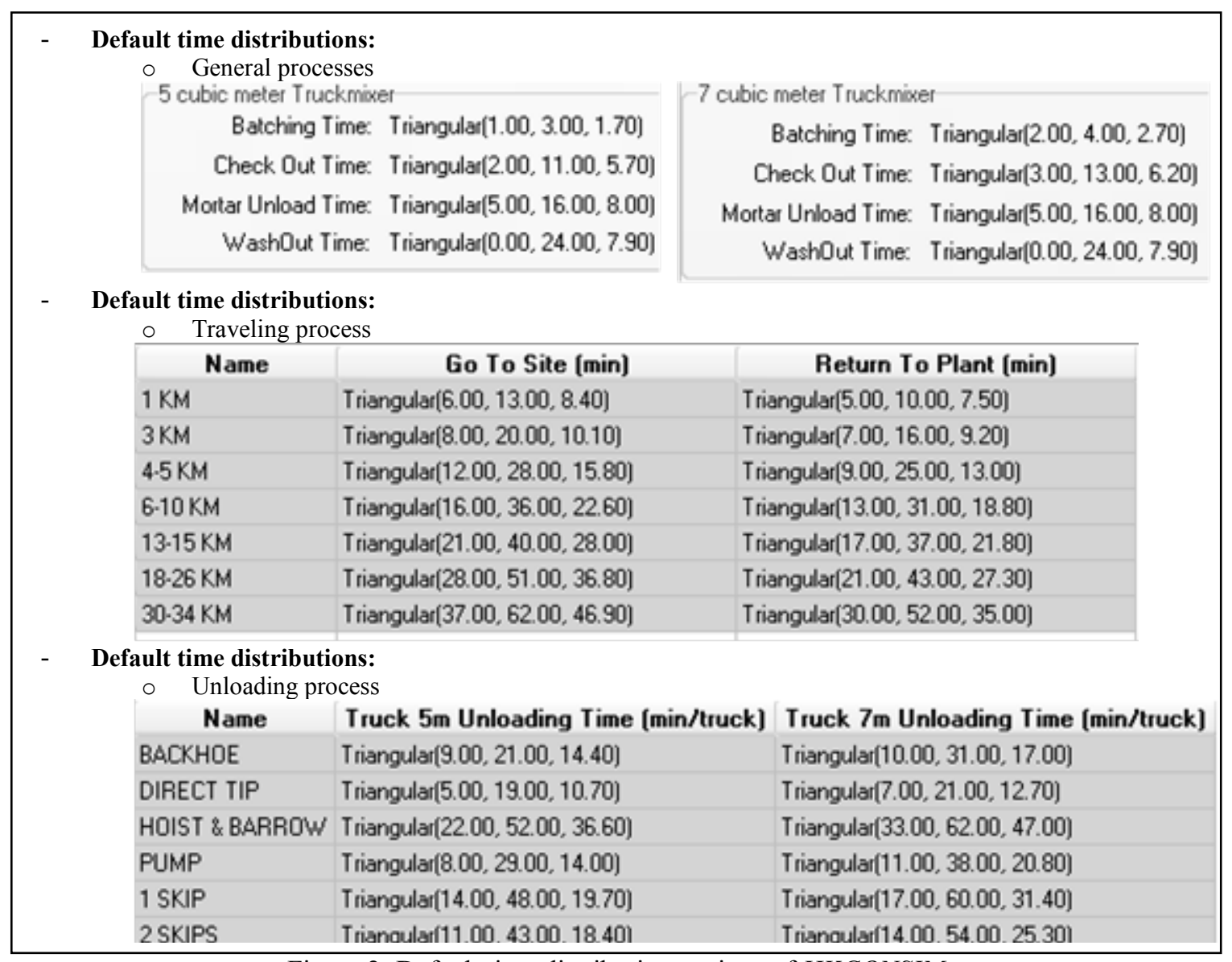

Figure 2: Default time distribution settings of HKCONSIM 


\section{Lu and Lam}

Table 2: Unloading times for several large pour orders

\begin{tabular}{|c|c|c|c|c|c|c|}
\hline \multirow[t]{2}{*}{$\begin{array}{l}\text { Site } \\
\text { ID }\end{array}$} & \multicolumn{3}{|c|}{$\begin{array}{c}\text { Triangular distribution for } \mathrm{TM} 5 \mathrm{~m}^{3} \\
(\mathrm{~min} / \mathrm{truck})\end{array}$} & \multicolumn{3}{|c|}{$\begin{array}{c}\text { Triangular distribution for } \mathrm{TM} 7 \mathrm{~m}^{3} \\
(\mathrm{~min} / \text { truck) }\end{array}$} \\
\hline & Optimistic & Most likely & Pessimistic & Optimistic & Most likely & Pessimistic \\
\hline 1 & 9 & 11 & 24 & 11 & 13 & 27 \\
\hline 4 & 10 & 15 & 28 & 14 & 20 & 34 \\
\hline 5 & 14 & 19 & 23 & 17 & 25 & 35 \\
\hline 7 & 9 & 11 & 15 & 11 & 15 & 21 \\
\hline 8 & 14 & 17 & 30 & 16 & 28 & 35 \\
\hline 10 & 11 & 19 & 33 & 14 & 23 & 42 \\
\hline 11 & 24 & 29 & 33 & 29 & 35 & 40 \\
\hline
\end{tabular}

\subsection{Performance Measures}

The development of a unified quantitative performance measure is critical to evaluating simulated scenarios, and thereby, optimizing the simulated system of HKCONSIM with respect to the truck-dispatching schedule and the truckmixer resource provision ( $\mathrm{Lu}$ et al. 2003). A confidence level on the performance measure should also be established due to the probabilistic and stochastic nature of simulation modeling (e.g. the uncertainty in activity duration and the variability in resource allocation in HKCONSIM). In the current case study, the performance measure of "total operations inefficiency" (TOI) is chosen for evaluating alternatives and determining the optimum state of the system. TOI denotes the total unproductive resource time incurred on all the building sites served by the RMC plant in one-day delivery operations by adding up the total queuing time of mixer trucks on sites and the total idle time of site crews. Hence, the less the TOI value, the less truck queuing and site idleness experienced within the whole system, and the higher the resource utilization rates of mixer trucks and site crews together with the higher the concrete delivery service level achieved by the RMC plant.

Running the HKCONSIM simulation - subject to the actual resource configurations (two batching bays, twenty-nine $7-\mathrm{m}^{3}$ trucks and fifteen $5-\mathrm{m}^{3}$ trucks) and site order requirements- has resulted in an average of $2720 \mathrm{~min}$ TOI. Note the TOI value from simulation refers to the average of a distribution, resulting from randomly sampling the simulated system for 500 times (i.e. 500 Monte Carlo duplications) as shown in Figure 3. The TOI distribution's appearance resembles a bell-shaped normal distribution and the $95 \%$ confidence interval of the average TOI is determined as [2691, 2750]. It should be noted throughout the case study, the evaluation of a simulation scenario by use of HKCONSIM is consistently based on the average of TOI resulting from 500 Monte Carlo duplications.

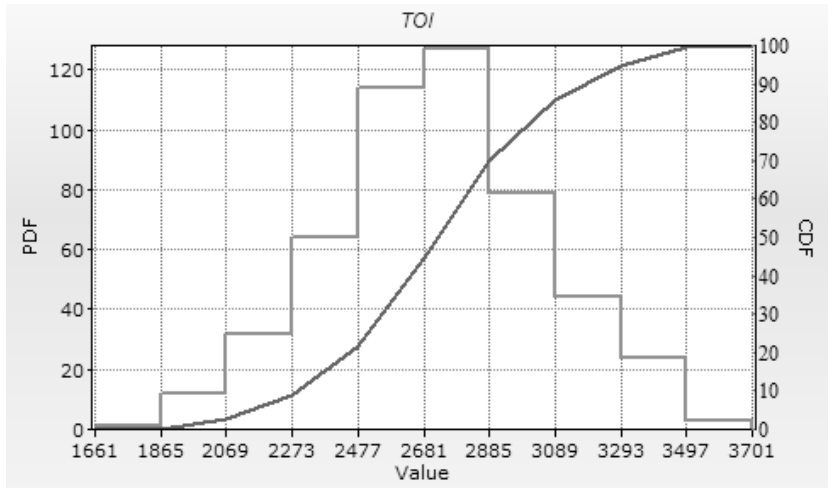

Figure 3: TOI Distribution resulting from case study with HKCONSIM

Careful analysis of actual operations data and delivery records has determined the actual TOI value to be $2670 \mathrm{~min}$, which is a close fit to the $2720 \mathrm{~min}$ average TOI derived from simulation. The slight difference (50 min) can be attributed to the fact that the actual TOI is not a statistical descriptor of the system performance as the simulated TOI, but a one-time observation from executing the actual system. The high TOI value has also exposed the poor matching performance between supply and demand in the real world (i.e. 2670 min truck queuing plus crew idle time on 13 sites or 205 min per site).

Two site-based performance ratios given by Anson and Wang (1998) imply the average number of trucks seen on a site and the working percentage of the site crew's time respectively, and are instrumental in evaluating system performances and further validating HKCONSIM simulation. They are (1) the truck provision ratio (TH/PD\%), defined as the truck provision hours on site over the pour duration, and (2) the site idleness ratio (SI/PD\%), defined as the site idle time over the pour dura- 
tion. A diagrammatic performance measure can be devised for the one-plant-multisite concrete delivery system by correlating the two ratios in a scatter plot (Figure 4). The overall trend among all sites can be observed as: with the increase of the truck provision ratio, the site idleness ratio decreases. The ideal performance is to cluster all sites into the "cost-efficient" zone, where the truck provision ratio is within $150 \%$ and the site idleness ratio under $20 \%$ (Anson and Wang 1998). The site idleness ratio of $20 \%$ indicates the concrete supply is interrupted in one fifth of the overall pour duration. The truck provision ratio of $150 \%$ can be interpreted as one or two truckmixers residing on site at one time over the pour duration. Note, according to Anson and Wang (1998), the definition of the above ideal performance thresholds along with the "cost-efficient" zone was arbitrary and based on statistical analysis of actual operations data and general perception by site personnel.

Since the definition of TOI also takes into account the truck queuing time on site and the crew idle time, TOI can be closely connected with the above diagrammatic measure based on the two ratios. Note the truck queuing is the unproductive portion of truck provision time on site and should be minimized along with the crew idle time in order to enhance the overall system performance. Therefore, if the TOI of a HKCONSIM simulation can be minimized through optimization, it is expected that the diagrammatic measure will automatically reach its ideal state by clustering all the dots within the "costefficient" zone. This connection will be clearly illustrated in the ensuing optimization experiments designed of our case study. To further validate the simulation model, similar to the measure of TOI, the diagrammatic measures resulting from actual records and simulation are contrasted in Figures $4 \mathrm{a}$, b. Figure $4 \mathrm{~b}$ gives the correlation pattern of the two performance ratios resulting from the averaged results of 500 Monte Carlo simulation runs, which is observed to well match the actual case as given in Figure $4 \mathrm{a}$.

As seen from the above validation case, the HKCONSIN model can serve as a useful parallel to the actual system for gaining more insights of the actual system and enhancing the performance of the actual system. In order to demonstrate how to improve the current practices by taking advantage of the optimization feature within HKCONSIM, the following sections postulate three scenarios with practical implications and investigate each by use of HKCONSIM.

Figure 4a. Based on Actual Data

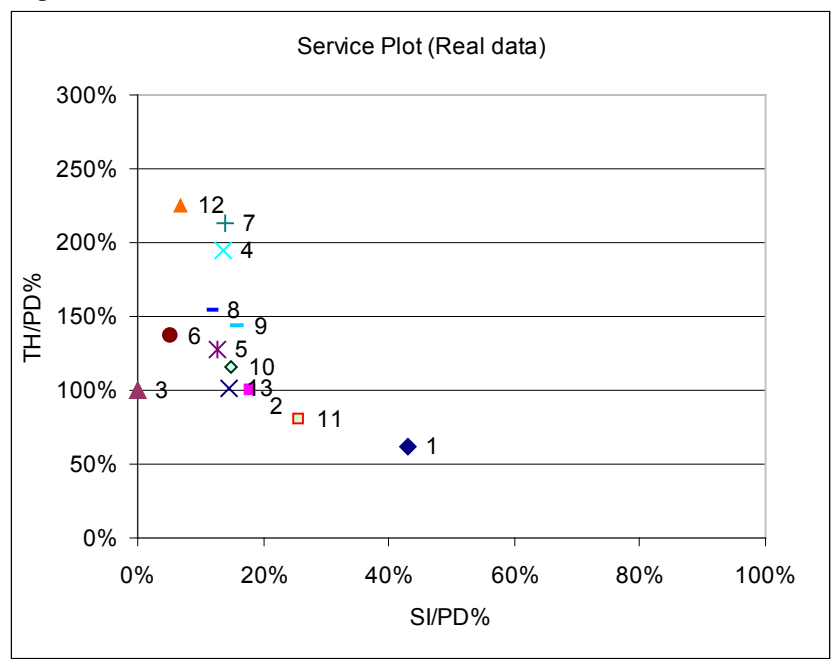

Figure 4: Contrasting the diagrammatic measures resulting from actual records and simulation
Figure 4b. Based on Simulation Results

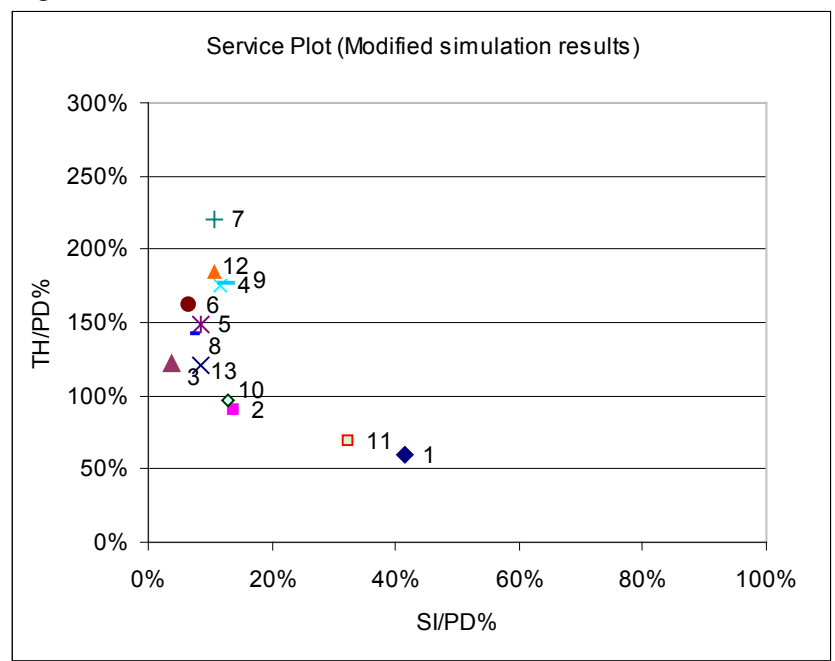

\section{ROJECT INITIATION}

\subsection{Scenario 1}

With the same mixer truck fleet $\left(297-\mathrm{m}^{3}\right.$ trucks and $155-\mathrm{m}^{3}$ ones), can the plant operator improve the delivery service by better marshalling the truck dispatching?

In the actual case, the TOI stood as high as $2670 \mathrm{~min}-$ equivalent to the average of nearly 3.5 hours truck queuing plus site idling as per site. Figure $4 \mathrm{a}$ also reveals in sites no. 11 and 1 the crews were idle over $20 \%$ of the pour time (due mainly to late concrete truck arrivals), while sites no. 12 and 7 experienced considerable truck bunching with over $200 \%$ truck provision ratio recorded. So how can the plant operator provide uninterrupted concrete delivery service to all site customers, while reducing truck bunching on site? 
Based on a valid HKCONSIM simulation, optimization analysis can be performed to fine-tune the inter-arrival time for each site within a certain limit of the original estimates (e.g. $\pm 20 \mathrm{~min}$ ); as a result, an optimum guide can be derived to assist the plant operator in prioritizing site demands and marshalling the truck fleet in a more masterful way, thereby leading to minimization of truck queuing time and crew idle time on all the sites being served. The overall system performance is expected to be sensitive to adjustments on truck inter-arrival times (Smith 1998, Ying et al. 2005). In our case study, the optimization brought down the simulated TOI from the original $2720 \mathrm{~min}$ to $928 \mathrm{~min}$. This is equivalent to a significant decrease on the average of truck queuing plus site idling time per site from nearly 3.5 hours to $1 \mathrm{hr} 12 \mathrm{~min}$. Table 3 contrasts the inter-arrival time for each site before and after optimization. Note that for small pours (sites no. 2 and 3 ) entailing only one truck delivery, optimization of the inter-arrival time is not applicable. On the remaining eight pours the optimization had prolonged the time gap between dispatching consecutive trucks by 1 to $13 \mathrm{~min}$; on three other sites, the time gap had been reduced by 2 to $8 \mathrm{~min}$. Moreover, improvements on system performance are also clearly demonstrated in the scatter plot that correlates the two performance ratios (Figure 5). In Figure 5, all sites have been clustered into the "cost efficient" zone bounded by the $150 \%$ truck provision ratio and the $20 \%$ site idleness ratio. In short, the site demand in terms of the estimate of the inter-arrival time of truck deliveries is found to exert substantial effects upon the overall delivery service level; and optimization of the interarrival times for all sites by HKCONSIM helps draw up the best concrete production schedule, thereby significantly enhancing the performance of a concrete plant in utilizing the trucks available to meet demands from multiple site clients.

Table 3: Scenario 1: inter-arrival time for each site before and after optimization

\begin{tabular}{c|c|c|c}
\hline $\begin{array}{c}\text { Site } \\
\text { ID }\end{array}$ & $\begin{array}{c}\text { Original Inter- } \\
\text { arrival time }\end{array}$ & $\begin{array}{c}\text { Optimum } \\
\text { Inter- } \\
\text { arrival time }\end{array}$ & Change \\
\hline 1 & 25 & 20 & -5 \\
\hline 2 & - & N/A & N/A \\
\hline 3 & - & N/A & N/A \\
\hline 4 & 20 & 24 & +4 \\
\hline 5 & 24 & 27 & +3 \\
\hline 6 & 25 & 38 & +13 \\
\hline 7 & 14 & 18 & +4 \\
\hline 8 & 25 & 28 & +3 \\
\hline 9 & 20 & 29 & +3 \\
\hline 10 & 30 & 31 & +9 \\
\hline 11 & 40 & 32 & -8 \\
\hline 12 & 20 & 29 & +9 \\
\hline 13 & 30 & 32 & -2 \\
\hline
\end{tabular}

\begin{tabular}{|c|c|c|c|}
\hline \multicolumn{2}{|c|}{ Select Site: } & \multicolumn{2}{|l|}{ Average } \\
\hline ID & Name & TH/PD & SI/PD \\
\hline 0 & Site1 & 91.14 & 16.78 \\
\hline 1 & Site2 & 103.03 & 7.54 \\
\hline 2 & Site3 & 117.17 & 4.67 \\
\hline 3 & Site 4 & 108.01 & 7.66 \\
\hline 4 & Site5 & 107.45 & 6.18 \\
\hline 5 & Site6 & 89.07 & 16.91 \\
\hline 6 & Site 7 & 95.82 & 13.30 \\
\hline 7 & Site8 & 109.33 & 6.60 \\
\hline 8 & Site9 & 99.19 & 14.76 \\
\hline 9 & Site10 & 92.75 & 14.87 \\
\hline 10 & Site11 & 95.10 & 9.14 \\
\hline 11 & Site12 & 98.32 & 14.42 \\
\hline 12 & Site13 & 104.85 & 12.99 \\
\hline
\end{tabular}

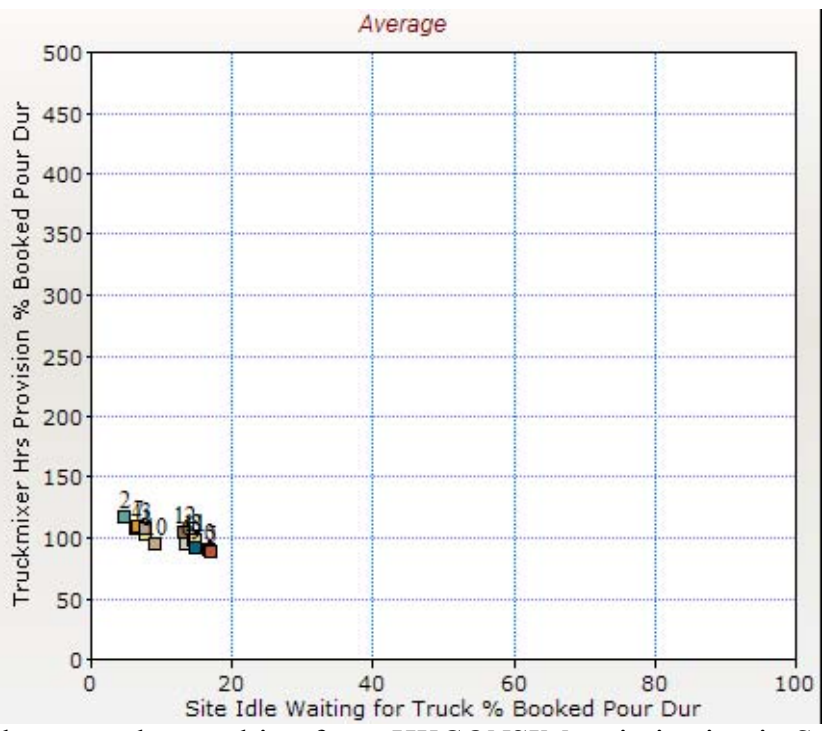

Figure 5: Site-specific performance ratios and scatter plot resulting from HKCONSIM optimization in Scenario 1 


\subsection{Scenario 2}

Can the concrete plant utilize fewer trucks to serve the 13 site clients without compromising the concrete-delivery service?

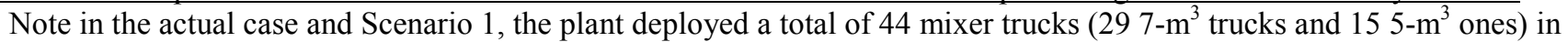
handling the 13 concrete pours over one working day. In addition to inter-arrival times, HKCONSIM can also help the plant operator optimize the configuration of the truck fleet, aimed to utilize fewer truck resources to achieve the similar service level. With consideration of the cost and availability constraints of truck resources and the actual site demand (a total of 966 $\mathrm{m}^{3}$ to 13 sites), the quantities of big trucks $\left(7 \mathrm{~m}^{3}\right)$ and small trucks $\left(5 \mathrm{~m}^{3}\right)$ were set to be bounded on $[15,25]$ and $[10,15]$ respectively before optimization. By adjusting the truck quantities and the inter-arrival times simultaneously, the optimization analysis eventually yielded an optimum solution of $966 \mathrm{~min}$ TOI (which is marginally higher than the 928 min TOI of Scenario 1), entailing 20 big trucks and 10 small ones only (i.e. a total of 14 fewer trucks than Scenario 1). The inter-arrival times associated with the optimum solution are given in Table 4 and listed against results from Scenario 1. The changes to interarrival times in Scenario 2 are noted to be trivial (within the limit of $\pm 2 \mathrm{~min}$ ), which indicates that the system optimization is largely enabled by streamlining the truckmixer fleet. Thus, the plant operator is advised to keep her original concrete production schedule but use a much leaner truckmixer fleet in order to achieve cost-efficiency and customer satisfaction.

Table 4: Scenario 2: inter-arrival time for each site before and after optimization

\begin{tabular}{|c|c|c|c|}
\hline $\begin{array}{l}\text { Site } \\
\text { ID }\end{array}$ & $\begin{array}{c}\text { Scenario 1: } \\
44 \text { trucks } \\
\text { Inter- } \\
\text { arrival } \\
\text { time }\end{array}$ & $\begin{array}{c}\text { Scenario 2: } \\
30 \text { trucks } \\
\text { Inter- } \\
\text { arrival time }\end{array}$ & Change \\
\hline 1 & 20 & 20 & 0 \\
\hline 2 & N/A & N/A & N/A \\
\hline 3 & N/A & N/A & N/A \\
\hline 4 & 24 & 26 & +2 \\
\hline 5 & 27 & 29 & +2 \\
\hline 6 & 38 & 38 & 0 \\
\hline 7 & 18 & 18 & 0 \\
\hline 8 & 28 & 30 & +2 \\
\hline 9 & 29 & 31 & +2 \\
\hline 10 & 31 & 30 & -1 \\
\hline 11 & 32 & 33 & +1 \\
\hline 12 & 29 & 29 & 0 \\
\hline 13 & 32 & 31 & -1 \\
\hline
\end{tabular}

The site-specific performance ratios are shown in the scatter plot of Figure 6. With the truck fleet being streamlined, the overall concrete-delivery service level and the site productivity level still remain satisfactory, as evidenced by both TOI and the scatter plot. In short, the truck resources are found to be oversupplied in both the actual case and Scenario 1; and reconfiguration of the truck fleet by HKCONSIM helps cut the resource cost of the plant by using 14 less trucks while maintaining the similar level of delivery service as achieved in Scenario 1. 


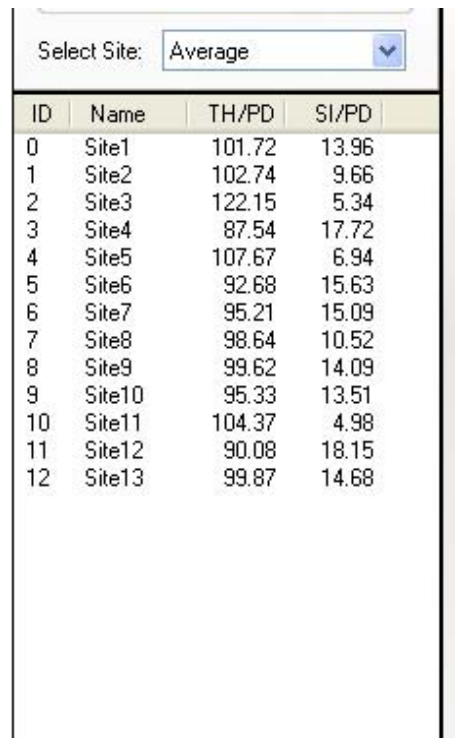

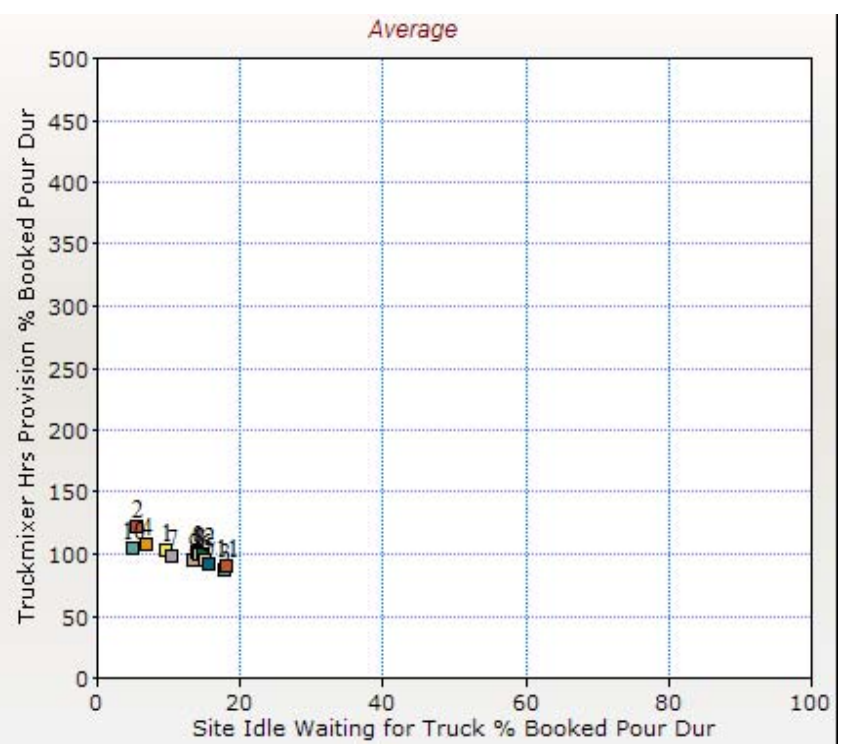

Figure 6: Site-specific performance ratios and scatter plot resulting from HKCONSIM optimization in Scenario 2

\subsection{Scenario 3}

Can the plant operator further improve the concrete-delivery performance by adjusting the pour start time on several large pours?

According to the real-world business practice, site contractors normally give the flexibility to the concrete plant in rearranging the pour start time (earlier or later within certain limits) as long as continuous concrete delivery service can be guaranteed. In the 3rd optimization scenario, the first truck arrival time for thirteen pours in our case study were allowed to be adjusted within the limit of $\pm 30 \mathrm{~min}$, while the quantities of big trucks and small trucks were bounded on the same ranges as in Scenario 2. The optimization results show that $898 \mathrm{~min}$ TOI was achieved with the use of a total of 29 trucks (22 big trucks and 7 small trucks). Hence, with reference to Scenario 2 (966 min TOI and 30 trucks in total) it is inferred that the plant operator could possibly obtain further improvement on the overall system performance (i.e. about 30 min less queuing/idle time on all sites) by use of 1 less truck. Comparisons are made in Table 5 on the pour start time and the inter-arrival time on each pour as compiled from the optimum results of Scenarios 2 and 3. Changes on pour start times are notable ( -30 to +25 min); in contrast, only minor adjustments (within $5 \mathrm{~min}$ ) had occurred to inter-arrival times. The resulting site performance ratios for Scenario 3 are shown in the scatter plot of Figure 7. In comparison with the previous Scenarios 1 and 2, the changes of clustering patterns in optimum solutions are not discernible, with all sites falling into the "cost efficient" zone in Figure 7. In short, the resulting changes to the TOI, the inter-arrival times, and the quantity of truck resources by rearranging the pour start times are not significant. And the system can be further fine-tuned by a small margin. 


\section{Lu and Lam}

\begin{tabular}{|c|c|c|c|}
\hline \multicolumn{2}{|c|}{ Select Site: } & Average & $\checkmark$ \\
\hline ID & Name & TH/PD & SI/PD \\
\hline 0 & Site1 & 99.43 & 13.37 \\
\hline 1 & Site2 & 103.52 & 7.92 \\
\hline 2 & Site3 & 108.54 & 7.01 \\
\hline 3 & Site4 & 98.89 & 10.76 \\
\hline 4 & Site5 & 93.89 & 11.70 \\
\hline 5 & Site6 & 99.31 & 11.93 \\
\hline 6 & Site7 & 94.58 & 13.89 \\
\hline 7 & Site8 & 102.24 & 8.92 \\
\hline 8 & Site9 & 91.63 & 18.58 \\
\hline 9 & Site10 & 100.80 & 11.27 \\
\hline 10 & Site11 & 106.96 & 4.30 \\
\hline 11 & Site12 & 98.15 & 15.08 \\
\hline 12 & Site13 & 109.59 & 10.33 \\
\hline
\end{tabular}

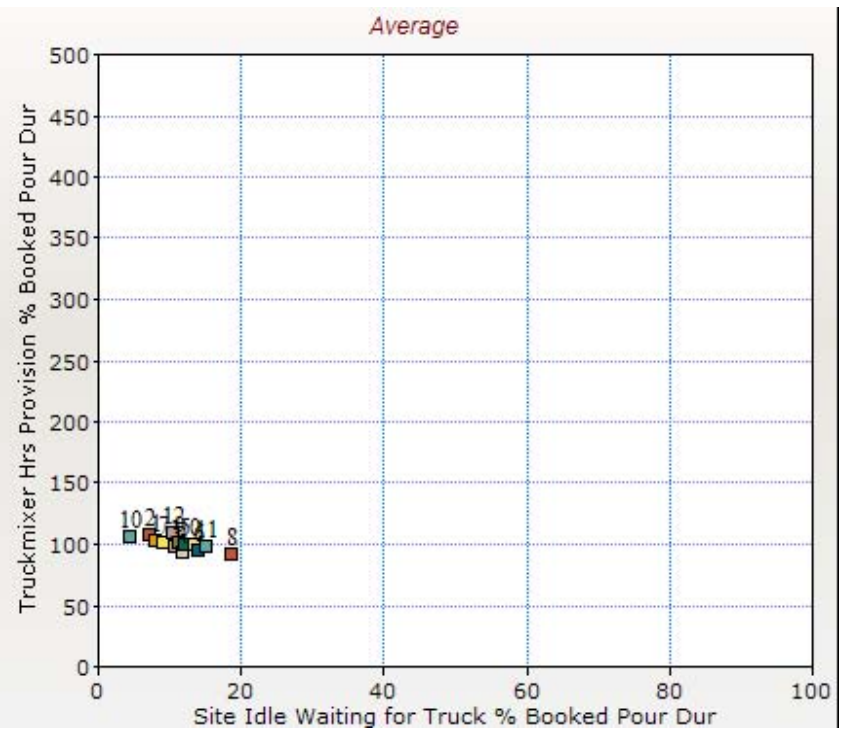

Figure 7: Site-specific performance ratios and scatter plot resulting from HKCONSIM optimization in Scenario 3

\section{CONCLUSION}

Due to the perishable nature of concrete, the batching and delivery operation of a ready mixed concrete (RMC) plant is a classic example of Just-In-Time (JIT) construction system. The service levels achieved together with the utilization levels achieved for the resources involved are governed by the subtle interactions between the supply and demand factors. Nonetheless, the current industry practices for scheduling concrete production still largely rely on managerial experiences and heuristic methods, falling short on any effective, straightforward modeling and optimization means. This has undermined not only the efficiency and service of the RMC business, but also the productivity and quality of concrete construction in building sites.

Research has proven the power and capability of the simulation technology in tackling the concrete production systems subject to practical constraints. To confront the complexity, uncertainty and variability within a one-plant-multisite RMC production system of practical size, we have developed a special-purpose simulation tool called HKCONSIM for rapidly building a simulation model for a typical one-plant-multisite system of concrete production and delivery based on a simplified discrete-event simulation approach. To automatically identify the optimum solution through simulation, evolutionary computing-based optimization algorithms have been integrated with HKCONSIM to augment simulation's power in dealing with complex RMC operation planning. In this research, particular emphasis has been placed on validation and application of this simulation-optimization integrated solution in a practical setting, as illustrated by a case study describing one-day operations of a Hong Kong RMC plant. The simulation model was validated first by comparing the simulation outputs against the actual records in light of the performance measure of the "Total Operations Inefficiency" and the scatter plot relating two site-specific ratios. Based on valid simulations, optimization analyses were carried out for three "what-if" scenarios postulated with practical implications.

We have gained the following insights from the case study: (1) the HKCONSIM model can serve as a useful parallel to the actual system for enhancing its performance; (2) optimization of the inter-arrival times for all sites by HKCONSIM helps draw up the best concrete production schedule, thereby significantly enhancing the performance of a concrete plant in utilizing the trucks available to meet demands from multiple site clients; (3) the truck resources are found to be oversupplied in the actual case, and reconfiguration of the truck fleet by HKCONSIM helps significantly cut the fleet size while maintaining the similar level of delivery service; (4) and the system can be further fine-tuned by a small margin by rearranging the pour start times on several large pours.

Finally, the latest HKCONSIM simulation system, powered by the optimization engine resulting from recent computing research, is ready to provide concrete plant managers with direct assistance in coping with the challenges of generating the best operation strategy in delivering concrete to multiple site clients. 


\section{ACKNOWLEDGMENTS}

The research presented in this paper was substantially funded by the Faculty of Construction and Land Use, Hong Kong Polytechnic University (Project A/C: 87QZ). Thanks are due to Prof. Michael Anson for his valuable input to the research over a prolonged period of many years.

\section{REFERENCES}

Alkoc, E., and F. Erbatur. 1998. Simulation in concreting operations: a comparison of models and resource combinations. Engineering Construction and Architectural Management, 5(2): 159-173.

Anson, M., and S.Q. Wang. 1994. Hong Kong performance yardsticks for concrete placing during building construction. HKIE transaction, 1(1): 1-18.

Anson, M., and S.Q. Wang. 1998. Performance of concrete placing in Hong Kong buildings. Construction Engineering and Management, 124(2): $116-124$.

Anson, M., S.L. Tang, and K.C. Ying. 2002. Measurement of the performance of ready mixed concreting resources as data for system simulation. Construction Management and Economics, 20(3): 237-250.

ASTM 2000. ASTM C94 - Standard Specification for Ready-Mixed Concrete, USA: American Society of Testing and Materials.

Christopher, M. 1992. Logistics and Supply Chain Management - Strategies for Reducing Costs and Improving Services, London: Pitman.

Chua, D.K.H., and G.M. Li. 2002. RISim: resource-interacted simulation modeling in construction. Construction Engineering and Management, 128(3): 195-202.

Feng, C.W., T.M. Cheng, and H.T. Wu. 2004. Optimizing the schedule of dispatching RMC trucks through genetic algorithms. Automation in Construction, 13: 327-340.

Feng, C.W., and H.T. Wu. 2006. Integrating fmGA and CYCLONE to optimize the schedule of dispatching RMC trucks. $A u$ tomation in Construction, 15, 186-199.

Hegazy, T., and M. Kassab. 2004. Resource optimization using combined simulation and genetic algorithms. Construction Engineering and Management, 129(6): 698-705.

Lu, M. 2003. Simplified discrete-event simulation approach for construction simulation. Construction Engineering and Management, 129(5): 537-546.

Lu, M. 2002. HKCONSIM: a simulation platform for planning and optimizing concrete plant operations in Hong Kong. Proc., Int. Conf. on Innovation \& Sustainable Development of Civil Engineering. in the 21st Century, 278-283, Aug. 2002, HKIE \& CCES, Beijing, China

Lu, M., M. Anson, S.L. Tang, and K.C. Ying. 2003. HKCONSIM: a practical simulation solution to planning concrete plant operations in Hong Kong. Construction Engineering and Management, 129(5): 547-554.

Lu, M., and H.C. Lam. 2005. Optimized concrete delivery scheduling using combined simulation and genetic algorithms. In Proceedings of the 2005 Winter Simulation Conference, eds. M. E. Kuhl, N. M. Steiger, F. B. Armstrong, and J. A. Joines, 2572-2580. Piscataway, New Jersey: Institute of Electrical and Electronics Engineers, Inc.

Lu, M., D.P. Wu, and J.P. Zhang. 2006. A particle swarm optimization-based approach to tackling simulation optimization of stochastic, Large-Scale and Complex Systems. Lecture Notes in Computer Science, 3930: 528-537, Springer Berlin Heidelberg.

Pidd, M. 1992. Computer Simulation in Management Science, 3rd ed., Chichester, New York: John Wiley and Sons Ltd.

Pritsker, A. 1986. Introduction to Simulation and SLAM II. New York: John Wiley and Sons, Inc.

Riley, M.J., and D.R. Towill. 2001. Business systems engineering- can it work in construction? New Civil Engrg. Int., Institute of Civil Engineers, March 2001, 44-49.

Sawhney, Z., O. Abudayyeh, and T. Chaitavatputtiporn. 1999. Modeling and analysis of concrete production plant using Petri nets. Computing in Civil Engineering., 13(3): 178-186.

Smith, S.D. 1998. Concrete placing analysis using discrete-event simulation. Proc., Instn. Civ. Engrs Structs \& Bldgs, 128(4): 351-358.

Tommelein, I., and A.E.Y. Li. 1999. Just-in-time concrete delivery: mapping alternatives for vertical supply chain integration. Proc., the 7th Conf. of the Inter. Group for Lean Constr., Berkeley, CA, 97-108.

Ying, K.C., S.L. Tang, M. Anson, and M. Lu, 2005. An experiment to explore the potential of simulation for improving ready mixed concrete delivery to construction sites. HKIE Transactions, 12(3): 6-13. 
Zayed, T.M., and D. Halpin. 2001. Simulation of concrete batch plant production. Construction Engineering and Management, $127(2): 132-141$.

Zayed, T.M., and I. Minkarah. 2004. Resource allocation for concrete batch operation: case study. Construction Engineering and Management, 130(4): 560-569.

\section{AUTHOR BIOGRAPHIES}

MING LU is Associate Professor of Construction Engineering \& Management of the Department of Civil and Structural Engineering, the Hong Kong Polytechnic University. He received a Ph.D. degree from the University of Alberta, Canada. His research interest is development of easy-to-apply, cost-effective methodologies of artificial intelligence and computer simulations for construction engineering and project management. Dr Lu proposed the Simplified Discrete-Event Simulation Approach (SDESA) for construction simulation and has led the research effort of developing the SDESA computer platform. His email <cemluepolyu.edu.hk>.

HOI-CHING LAM received his B. Eng degree of Civil and Structural Engineering, M. Phil. degree from the Hong Kong Polytechnic University, and now is a Research Associate of Department of Civil and Structural Engineering at the Hong Kong Polytechnic University, working on model simulation and optimization, along with construction management. His email is <ceching@polyu.edu.hk> 